\title{
GxE Interactions Analysis of Wheat Genotypes Evaluated Under Peninsular Zone of the Country by AMMI Model
}

\author{
Ajay Verma, Gyanendra Pratap Singh \\ Crop Improvement Division, Indian Council of Agricultural Research-Indian Institute of Wheat \& Barley Research, Karnal, India
}

\section{Email address:}

ajay.verma1@icar.gov.in (A. Verma)

\section{To cite this article:}

Ajay Verma, Gyanendra Pratap Singh. GxE Interactions Analysis of Wheat Genotypes Evaluated Under Peninsular Zone of the Country by AMMI Model. American Journal of Agriculture and Forestry. Vol. 9, No. 1, 2021, pp. 29-36. doi: 10.11648/j.ajaf.20210901.15

Received: December 7, 2020; Accepted: December 31, 2020; Published: January 30, 2021

\begin{abstract}
AMMI analysis of wheat genotypes had highlighted significant effects of environments, interactions and genotypes for the 2017-18 and 2018-19. Number of adaptability measures had been studied as per utilization of number of significant interaction principal components (IPCs). Total of interaction variations exploited by Type-1, 2, 3, 4 \& 5 measures were $45.5 \%, 66.3 \%, 75.9 \%$ \& 88.4\% respectively. Type-1 measures EV1, D1, ASTAB1 identified (G7, G6, G12) genotypes while SIPC1 selected (G14, G17, G2). EV2, D2, ASTAB2, ASV and ASV1 measures found (G7, G6, G4) as desirable genotypes. Analytic measures based on all significant IPCA's i.e. MASV and MASV1 settled for G6, G7, and G3. Adaptability measures GAI, HM, PRVG \& MHPRVG observed G13, G4, and G12 genotypes would be of stable adaptations. Biplot analysis seen largest cluster comprised D3, D5, EV2, EV3, EV5, ASTAB3, ASTAB5, MASV1, MASV and Standard deviation measures. Genotypes were ranked G9, G11, and G6 by values of EV1, D1 \& ASTAB1 for second year of study. D2, ASV, ASV1, EV2 \& ASTAB2 observed (G9, G6, and G11) as adaptable genotypes. MASV \& MASV1 measures also supported G9, G6, G11 genotypes for the considered locations of the zone. Studied measures were clustered in three groups in graphical analysis. Three clusters were observed among studied measures by biplot analysis. Measures EV1, EV2, EV3, D1, D2, D3, ASV, ASV1, MASV, MASV1, ASTAB1, and ASTAB2 \& ASTAB3 formed largest cluster.
\end{abstract}

Keywords: AMMI, BLUP, PRVG, MHPRVG, Biplots

\section{Introduction}

Very well wide adaptation of wheat made it possible to cultivate an important cereal in most of the countries [18]. Multi location trials have been conducted to evaluate the yield performance of several genotypes simultaneously [7]. Field evaluation of genotypes have required an efficient analytic estimation procedure for GxE interactions [1]. Presence of cross over type GxE interactions mask the real potential of deserving genotypes for their specific and general adaptations [17]. Quite large number of analytic approaches have developed especially for adaptation behavior of genotypes $[15,2]$. Univariate parametric, nonparametric, multivariate models for additive and multiplicative nature of factors. Over exploited method Additive Main effects and Multiplicative Interaction (AMMI) advocated in agricultural research field experiments [8]. Large portion of the interactions sum of squares had been utilized by AMMI analysis to discriminate environments, adaptability of the genotypes to specific and general environmental conditions to harvest well yield [5]. This analysis mechanism has proved as an effective analysis with possible opportunities to research workers [6]. The current study was planned with clear objectives (i) Study number of AMMI based measures as per utilization of number of significant interaction principal components (ii) similarity \& dissimilarity among adaptability measures.

\section{Materials and Methods}

Peninsular zone comprises mainly of Maharashtra and Karnataka states of our country. Major three species of wheat viz T. aestivum, T. durum, and T. dicoccumare cultivated in this zone. Bread wheat cultivation is concentrated under irrigated environments, whereas, the cultivation of durum and dicoccum wheat is generally confined to rainfed/ 
restricted irrigation situation. Genotype by environment (GxE) interactions of seventeen advanced wheat genotypes at thirteen major locationsduring 2017-18 and eleven genotypes at elevenlocations in 2018-19 cropping season of the zone by AMMI model. Research field trials were conducted at centers of AICRP by randomized complete block designs with four replications. Recommended agronomic practices were followed to harvest good yield. Details of genotype parentage along with environmental conditions were reflected in tables $1 \& 2$ for ready reference. AMMI first calculate genotype and environment additive effect using analysis of variance (ANOVA) and then analyse residual from these model using principal components analysis (PCA). AMMI stability value
(ASV) proposed by Purchase [11] to quantify the stability measure by considering relative weight of IPCA 1 and IPCA scores. In certain cases where more than two IPCAs were significant, ASV failed to encompass all the variability explained by GxE interactions. Zali[20] attempted modified version ASV which would cover all available Interaction Principal Components. But in doing so, Zali interpreted the formula of ASV incorrectly compared to the original formula of Purchase $[11,12]$. In the present study the original MASV formula of Zali[20] and a revised version of MASV [2] were compared with other AMMI based measures of interaction effects. The description of widely used measures based on AMMI analysis was mentioned for completeness.

Table 1. AMMI analysis based measures

\begin{tabular}{|c|c|c|c|c|}
\hline Zobel [21] & 1994 & EV1 & EVF & $\mathrm{EV}=\sum_{n=1}^{N} \lambda_{i n}^{2} / n$ \\
\hline Snelleret al[16] & 1997 & SIPC1 & SIPCF & $\mathrm{SIPC}=\sum \lambda_{n}^{0.5} \gamma_{i n}$ \\
\hline Purchase et al [12] & 2000 & ASV & & 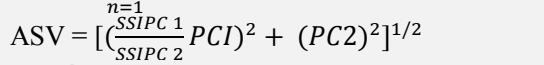 \\
\hline Annicchiarico [4] & 1997 & $\mathrm{D}$ & & $\mathrm{D}=\sqrt{\sum_{n=1}^{N} \underset{n}{\left(\lambda_{n} \gamma_{i n}\right)^{2}}}$ \\
\hline Rao and Prabhakaran [13] & 2005 & ASTAB & & $A S T A B=\sum \lambda_{n} \gamma_{n i}^{2}$ \\
\hline Zali et al [20] & 2012 & ASV1 & & 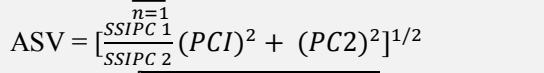 \\
\hline Zali et al [20] & 2012 & MASV & & $M A S V=\sqrt{\sum_{n=1}^{N-1} \frac{\operatorname{SSIPC}_{n}}{\operatorname{SSIPC}_{n+1}}\left(P C_{n}\right)^{2}}+\left(P C_{n+1}\right)^{2}$ \\
\hline Ajay et al [2] & 2019 & MASV1 & & $M A S V 1=\sqrt{\sum_{n=1}^{N-1}\left(\frac{S S I P C_{n}}{\operatorname{SSIPC}_{n+1}} P C_{n}\right)^{2}}+\left(P C_{n+1}\right)^{2}$ \\
\hline
\end{tabular}

Table 2. Parentage of wheat genotypes and environmental conditions (2017-18).

\begin{tabular}{|c|c|c|c|c|c|c|c|}
\hline Code & Genotype & Parentage & Code & Environments & Latitude & Longitude & $\begin{array}{l}\text { Mean sea } \\
\text { level }\end{array}$ \\
\hline G1 & AKAW 4924 & DL-9-65-2/AKW1071-1-2 & E1 & Arabhavi & $15^{\circ} 84^{\prime} \mathrm{N}$ & $74^{\circ} 51^{\prime} \mathrm{E}$ & $625 \mathrm{~m}$ \\
\hline $\mathrm{G} 2$ & GW 491 & HD2808/HI1516//PBW573 & E2 & Dharwad & $15^{\circ} 27^{\prime} \mathrm{N}$ & $75^{\circ} 0^{\prime} \mathrm{E}$ & $724 \mathrm{~m}$ \\
\hline G3 & GW 493 & HW2045//HI 1183/PCE2555 & E3 & Kalloli & $16^{\circ} 26^{\prime} \mathrm{N}$ & $74^{\circ} 86^{\prime} \mathrm{E}$ & $625 \mathrm{~m}$ \\
\hline G4 & DBW 235 & MELON//FILIN/MILAN/3/FILIN/4/TRCH/SRTU//KACHU & E4 & Karad & $17^{\circ} 17^{\prime} \mathrm{N}$ & $74^{\circ} 10^{\prime} \mathrm{E}$ & $577 \mathrm{~m}$ \\
\hline G5 & HI 1624 & GW322/PBW498 & E5 & Kolahpur & $16^{\circ} 41^{\prime} \mathrm{N}$ & $74^{\circ} 14^{\prime} \mathrm{E}$ & $578 \mathrm{~m}$ \\
\hline G6 & GW 495 & LOK54/RAJ4083 & E6 & Mahabaleshwar & $17^{\circ} 55^{\prime} \mathrm{N}$ & $73^{\circ} 39^{\prime} \mathrm{E}$ & $1322 \mathrm{~m}$ \\
\hline G8 & HI 8800 & HI8681/HI8663 & E8 & Nashik & $19^{\circ} 59^{\prime} \mathrm{N}$ & $73^{\circ} 47^{\prime} \mathrm{E}$ & $583 \mathrm{~m}$ \\
\hline G9 & MACS 6709 & ROLF07/4/BOW/NKT//CBRD/3/CBRD/5/FRET2/TUKURU//FRET2 & E9 & Niphad & $20^{\circ} 4^{\prime} \mathrm{N}$ & $74^{\circ} 6^{\prime} \mathrm{E}$ & $551 \mathrm{~m}$ \\
\hline G10 & HI 1625 & GAINT3/HW2045 & E10 & Nippani & $16^{\circ} 23^{\prime} \mathrm{N}$ & $74^{\circ} 22^{\prime} \mathrm{E}$ & $606 \mathrm{~m}$ \\
\hline G11 & PBW 770 & PBW585/4/BABAX//IRENA/KAUZ/3/HUITES & E11 & Parbhani & $19^{\circ} 15^{\prime} \mathrm{N}$ & $76^{\circ} 46^{\prime} \mathrm{E}$ & $413 \mathrm{~m}$ \\
\hline G12 & GW 492 & RAJ4040/HD2808 & E12 & Pune & $18^{\circ} 31^{\prime} \mathrm{N}$ & $73^{\circ} 51^{\prime} \mathrm{E}$ & $562 \mathrm{~m}$ \\
\hline G13 & MACS 6222 & HD2189*2/MACS2496 & E13 & Ugar - Khurd & $16^{\circ} 39^{\prime} \mathrm{N}$ & $74^{\circ} 49^{\prime} \mathrm{E}$ & $548 \mathrm{~m}$ \\
\hline G14 & DBW 168 & SUNSU/CHIBIA & & & & & \\
\hline G16 & MACS 6478 & CS/TH.SC//3*VN/3/MIRLO/BUC/4/MILAN/5/TILHI & & & & & \\
\hline G17 & UAS 428 & GREEN-14/YAN-10/AUK/UAS402 & & & & & \\
\hline
\end{tabular}

Table 3. Parentage details of genotypes along with environmental conditions (2018-19).

\begin{tabular}{|c|c|c|c|c|c|c|c|}
\hline Code & Genotype & Parentage & Code & Environments & Latitude & Longitude & Mean sea level \\
\hline G1 & PBW 823 & T. boeoticum $4992 / 2 * \mathrm{PDW} 274 / / 2 * \mathrm{PBW} 703$ & E1 & Niphad & $20^{\circ} 4^{\prime} \mathrm{N}$ & $74^{\circ} 6^{\prime} \mathrm{E}$ & $551 \mathrm{~m}$ \\
\hline $\mathrm{G} 2$ & UAS 428 & GREEN-14/YAN-10/AUK/UAS402 & E2 & Pune & $18^{\circ} 31^{\prime} \mathrm{N}$ & $73^{\circ} 51^{\prime} \mathrm{E}$ & $562 \mathrm{~m}$ \\
\hline G3 & DDW 49 & PDW314/PDW233 & E3 & Akola & $20^{\circ} 42^{\prime} \mathrm{N}$ & $77^{\circ} 0^{\prime} \mathrm{E}$ & $292 \mathrm{~m}$ \\
\hline G4 & UAS 3001 & UAS259/GW322//HI 977 & E4 & Parbhani & $19^{\circ} 15^{\prime} \mathrm{N}$ & $76^{\circ} 46^{\prime} \mathrm{E}$ & $413 \mathrm{~m}$ \\
\hline G5 & MACS 3949 & STOT//ALTAR84/ALD/3/THB/CEP7780//2*MUSK_4 & E5 & Nasik & $19^{\circ} 59^{\prime} \mathrm{N}$ & $73^{\circ} 47^{\prime} \mathrm{E}$ & $583 \mathrm{~m}$ \\
\hline G6 & MACS 6222 & HD2189*2/MACS2496 & E6 & Kolhapur & $16^{\circ} 41^{\prime} \mathrm{N}$ & $74^{\circ} 14^{\prime} \mathrm{E}$ & $578 \mathrm{~m}$ \\
\hline
\end{tabular}




\begin{tabular}{|c|c|c|c|c|c|c|c|}
\hline Code & Genotype & Parentage & Code & Environments & Latitude & Longitude & Mean sea level \\
\hline G8 & DDW 48 & HI8498/PDW233//PDW291 & E8 & Arbhavi & $15^{\circ} 84^{\prime} \mathrm{N}$ & $74^{\circ} 51^{\prime} \mathrm{E}$ & $625 \mathrm{~m}$ \\
\hline G9 & MACS 6478 & CS/TH.SC//3*VN/3/MIRLO/BUC/4/MILAN/5/TILHI & E9 & Kalloli & $16^{\circ} 26^{\prime} \mathrm{N}$ & $74^{\circ} 86^{\prime} \mathrm{E}$ & $625 \mathrm{~m}$ \\
\hline G10 & HD $3343 \mathrm{M}$ & $\mathrm{HI} 1500 / 2 * \mathrm{GW} 322$ & E10 & Nippani & $16^{\circ} 23^{\prime} \mathrm{N}$ & $74^{\circ} 22^{\prime} \mathrm{E}$ & $606 \mathrm{~m}$ \\
\hline G11 & WHD 963 & $\begin{array}{l}\text { BCRIS/BICUM/LLARETA } \\
\text { INIA/3/DUKEM_12/2*RASCON_21/5/SOMAT_3/GREEN_22/4/ } \\
\text { GODRIN/GUTROS/DUKEM/3/THKNEE } 11\end{array}$ & E11 & Ugar-Khurd & $16^{\circ} 39^{\prime} \mathrm{N}$ & $74^{\circ} 49^{\prime} \mathrm{E}$ & $548 \mathrm{~m}$ \\
\hline
\end{tabular}

AMMI analysis was performed using AMMISOFT version 1.0, available at https://scs.cals.cornell.edu/people/ hughgauch/ and SAS software version 9.3. AMMI based measures were compared with recent analytic measures of adaptability calculated as the relative performance of genetic values (RPGV) and MHGV (Harmonic mean of Genetic Values), based on the harmonic mean of the genotypic values across different environments. Another harmonic mean based measure of the relative performance of the genotypic values (MHRPGV) for the simultaneous analysis of stability, adaptability and yield [14].

$$
\mathrm{RPGV}_{\mathrm{ij}}=\mathrm{GV}_{\mathrm{ij}} / \mathrm{GV}_{\mathrm{i}}
$$

$\mathrm{MHGV}_{\mathrm{i}}=$ Number of environments $/ \sum_{i=1}^{k} \frac{1}{X_{i}}$

MHRPGV $_{\text {i. }}=$ Number of environments $/ \sum_{j=1}^{k} \frac{1}{R P G V_{i j}}$

$G V_{i j}$ is the genotypic value of the $i$ genotype, in the $j$ environment, expressed as a proportion of the average in this environment. Geometric adaptability index (GAI) [10] was calculated as $\sqrt[n]{\prod_{\mathrm{k}=1}^{\mathrm{n}} \overline{\mathrm{X}}_{\mathrm{k}}}$; in which $\overline{\mathrm{X}}_{1}, \overline{\mathrm{X}}_{2}, \overline{\mathrm{X}}_{3, \ldots}, \overline{\mathrm{X}}_{\mathrm{m}}$ are the mean yields of the first, second and mth genotype across environments and $\mathrm{n}$ is number of environments. Genotypes with higher values of GAI are desirable.

\section{Results and Discussion}

Better understanding of the GxE interaction had been provided by AMMI analysis as this facilitated identification of general and specific adaptations of genotypes anddiscriminate environments. In fact AMMI exercised family of models with retaining $0,1,2$, or more significant interaction principal components (IPCs).

\subsection{First Year of Study (2017-18)}

Estimated sums of squares for GxE signal and GxE noise were $69.9 \%$ and $30.2 \%$ respectively

Sum of squares for GxE signal is 2.33 times that for genotypes main effects, implied, narrow adaptations are important for trials research dataset. First IPC1 alone is 1.52 times the genotypes main effects whereas GxE noise is 1.01 times the genotypes main effects. Discarding noise improves accuracy, increases repeatability, simplifies conclusions, and accelerates progress [6]. Highly significant environments (49.9), GxE interaction (21.4) and genotypes (6.4) were observed by ANOVA analysis. Diversity of considered locations had justified the selection of environments [3]. Explained variation of GxE interaction accounted by each of highly significant IPCA's, as type-1 measures benefited $45.5 \%$, type- 2 measures utilized $66.3 \%$, type 3 measures used up to $75.9 \%$, type- 5 measures used up to $88.4 \%$ of interaction variations, tough IPCA5, IPCA6 and IPCA7 contributed to the tune of $5.5,3.9$ and $2.9 \%$ respectively (Table 4 ). Use of AMMI derived measures upto first five IPCAs had been justified [9]. Smaller and large values of EV1 observed for (G7, G6, G12) and (G14, G11) while corresponding to D1 were (G7, G6, G12) and (G14, G11), SIPC1 for (G14, G17, G2) and (G11, G15) and for ASTAB1 were (G7, G6, G12) \& (G14, G11). EV2 measure pointed towards (G6, G7, G4) as desirable along with undesirable genotypes as (G15, G11) for values of D2 genotypes were $(\mathrm{G} 6, \mathrm{G} 7, \mathrm{G} 7)$ \& $(\mathrm{G} 15, \mathrm{G} 1)$, whereas as per criterion of SIPC2 were $(\mathrm{G} 2, \mathrm{G} 14, \mathrm{G} 5)$ \& (G15, G12) and ASTAB2 values favoured(G6, G7, G4) \& (G15, G11) (Tables 6 and 7).

Table 4. AMMI analysis of wheat genotypes evaluated in Peninsular Zone (2017-18).

\begin{tabular}{|c|c|c|c|c|c|c|}
\hline Source & Degrees of freedom & Mean Sum of Squares & Level of significance & $\%$ of Total SS & $\%$ of GxE SS & Cumulative\% SS by PCA's \\
\hline Treatments & 220 & 299.70 & $* * *$ & 77.70 & & \\
\hline Genotypes & 16 & 340.54 & $* * *$ & 6.42 & & \\
\hline Environments & 12 & 3526.27 & $* * *$ & 49.87 & & \\
\hline GxE interactions & 192 & 94.64 & $* * *$ & 21.41 & & \\
\hline IPC1 & 27 & 306.00 & $* * *$ & & 45.47 & 45.47 \\
\hline IPC2 & 25 & 151.14 & $* * *$ & & 20.79 & 66.26 \\
\hline IPC3 & 23 & 76.03 & $* * *$ & & 9.62 & 75.89 \\
\hline IPC4 & 21 & 61.18 & * & & 7.07 & 82.96 \\
\hline IPC5 & 19 & 52.36 & & & 5.47 & 88.43 \\
\hline IPC6 & 17 & 41.75 & & & 3.91 & 92.34 \\
\hline IPC7 & 15 & 35.34 & & & 2.92 & 95.26 \\
\hline Residual & 45 & 19.15 & & & & \\
\hline Error & 663 & 28.54 & & & & \\
\hline Total & 883 & 96.10 & & & & \\
\hline
\end{tabular}


Table 5. AMMI analysis of wheat genotypes evaluated in Peninsular Zone (2018-19).

\begin{tabular}{lllllll}
\hline Source & $\begin{array}{l}\text { Degrees of } \\
\text { freedom }\end{array}$ & $\begin{array}{l}\text { Mean Sum of } \\
\text { Squares }\end{array}$ & $\begin{array}{l}\text { Level of } \\
\text { significance }\end{array}$ & $\begin{array}{l}\text { \% of Total Sum of } \\
\text { Squares }\end{array}$ & $\begin{array}{l}\text { \% of GxE Sum of } \\
\text { Squares }\end{array}$ & $\begin{array}{l}\text { Cumulative\% SS by } \\
\text { PCA's }\end{array}$ \\
\hline Treatments & 120 & 259.51 & $* * *$ & 75.22 & \\
Genotypes & 10 & 445.46 & $* * *$ & 10.76 & & \\
Environments & 10 & 1823.52 & $* * *$ & 44.05 & & \\
GxE interactions & 100 & 84.51 & $* * *$ & 20.42 & 51.19 & 61.19 \\
IPC1 & 19 & 227.71 & $* * *$ & & 15.15 & 79.34 \\
IPC2 & 17 & 75.32 & $* * *$ & & 12.93 & 87.77 \\
IPC3 & 15 & 72.84 & $*$ & & 5.80 & 93.56 \\
IPC4 & 13 & 55.23 & & & 3.58 & 97.14 \\
IPC5 & 11 & 44.54 & & & & 98.85 \\
IPC6 & 9 & 33.63 & & & & \\
IPC7 & 7 & 20.63 & & & & \\
Residual & 9 & 10.76 & & & & \\
Error & 363 & 28.25 & & & & \\
Total & 483 & 85.71 & & & & \\
\hline
\end{tabular}

Table 6. Principal components analysis of genotypes (2017-18).

\begin{tabular}{|c|c|c|c|c|c|c|c|c|c|c|c|c|c|c|c|c|}
\hline $17-18$ & EV1 & EV2 & EV3 & EV5 & D1 & D2 & D3 & D5 & IPC1 & IPC2 & IPC3 & IPC4 & ASV & ASV1 & MASV & MASV1 \\
\hline G 1 & 0.0236 & 0.0153 & 0.0102 & 0.0150 & 4.53 & 4.88 & 4.88 & 5.76 & -1.4656 & 0.6547 & 0.0220 & -1.1971 & 2.26 & 3.27 & 2.74 & 3.76 \\
\hline G 2 & 0.0344 & 0.0391 & 0.0271 & 0.0275 & 5.46 & 7.14 & 7.19 & 7.87 & -1.7694 & -1.6394 & 0.3619 & -0.4245 & 3.09 & 4.20 & 3.98 & 5.55 \\
\hline G 3 & 0.0099 & 0.0050 & 0.0144 & 0.0180 & 2.92 & 2.93 & 4.19 & 5.09 & -0.9465 & 0.0541 & -1.1786 & 0.2523 & 1.40 & 2.07 & 2.30 & 2.89 \\
\hline G 4 & 0.0051 & 0.0037 & 0.0167 & 0.0228 & 2.10 & 2.36 & 4.14 & 5.51 & 0.6787 & 0.3855 & 1.3368 & -1.3635 & 1.08 & 1.53 & 2.75 & 3.16 \\
\hline G 5 & 0.0091 & 0.0387 & 0.0328 & 0.0216 & 2.81 & 6.39 & 6.82 & 6.95 & -0.9094 & -2.0497 & -0.9331 & 0.4016 & 2.45 & 2.86 & 4.16 & 5.52 \\
\hline G 6 & 0.0002 & 0.0034 & 0.0095 & 0.0090 & 0.39 & 1.84 & & & & 0.6406 & -0.9531 & & 0.67 & 0.70 & 1.92 & 2.28 \\
\hline G 7 & 0.0001 & 0.0035 & 0.0116 & 0.0257 & 0.23 & 1. & & & 48 & 0.6528 & -1.0767 & -1.3016 & 0.66 & 0.67 & 2.41 & 2.73 \\
\hline G 8 & 0.0142 & 0.0431 & 0.0287 & 0.0262 & 3.5 & 6.86 & 6.86 & 7.49 & 60 & -2.1040 & 0.0032 & -1. & 2.69 & 3.26 & 4.23 & 5.69 \\
\hline G 9 & 0.0085 & 0.0373 & 0.0355 & 0.0247 & 2.7 & 6.26 & 6 & 7. & 98 & 2.0 & 524 & 18 & 2.40 & 2.79 & 4.25 & 5.56 \\
\hline G 10 & 0.0517 & 0.0369 & 0.0279 & 0.0522 & 6.7 & 7.4 & 7. & 9.6 & 85 & 40 & 0.6426 & 1. & 3.41 & 4.88 & 4.38 & 5.91 \\
\hline G 11 & 0.0830 & 0.0612 & 0.0463 & 0.0335 & 8.4 & 9 & 9. & 1 & 59 & 76 & -0.8306 & 04 & 4.35 & 6.20 & 5.17 & 7.26 \\
\hline G 12 & 0.0019 & 0.0283 & 0.0564 & 0.0410 & 1.3 & 5.29 & 7.6 & 8 & 10 & 1.8329 & 2.1694 & -0.8676 & 1.94 & 2.05 & 4.78 & 5.84 \\
\hline G 13 & 0.0044 & 0.0110 & 0.0252 & 0.0380 & 1.9 & 35 & 5. & 7. & 53 & 1.0364 & 1.4972 & 1.4594 & 1.40 & 1.73 & 3.42 & 4.07 \\
\hline G 14 & 0.0857 & 0.0456 & 0.0311 & 0.0338 & 8.6 & 87 & 8. & 9. & 18 & -0.5804 & -0.2872 & 1.2459 & 4.17 & 6.13 & 4.46 & 6.40 \\
\hline G 15 & 0.0787 & 769 & 0.0737 & 0.0509 & 8.26 & 10.2 & 11 & 11.39 & 2.6753 & 2.1494 & -1.6781 & 1.0840 & 4.50 & 6.23 & 6.17 & 8.34 \\
\hline G 16 & 0.0097 & 0.0096 & 0.0219 & 0.0219 & 2.90 & 3.60 & 5.06 & 5.78 & & -0.7614 & 1.3962 & 0.2282 & 1.59 & 2.19 & 2.90 & 3.62 \\
\hline G 17 & 0.0797 & 0.0414 & 0.0311 & 0.0383 & 8.31 & 8.40 & 8.56 & 9.56 & -2.6910 & 0.4344 & 0.6605 & 0.7755 & 4.00 & 5.90 & 4.25 & 6.13 \\
\hline
\end{tabular}

$\mathrm{EV}=$ Eigenvector, $\mathrm{SIPC}=$ Sum of the value of the IPC Scores, $\mathrm{D}=$ Parameter of Annicchiarico; SIPC1 $=$ SIPC for first IPCA, SIPC $2=$ SIPC for first two IPCAs,, IPCA, principal component of interaction, ASV = AMMI stability value; MASV = Modified AMMI stability value; ASTAB = AMMI stability

Table 7. AMMI based estimates of genotypes (2017-18).

\begin{tabular}{|c|c|c|c|c|c|c|c|c|c|c|c|c|c|c|}
\hline & SIPC1 & SIPC2 & SIPC3 & SIPC5 & ASTAB1 & ASTAB2 & ASTAB3 & ASTAB5 & MEAN & STDEV & GAI & RPGV & MHRPGV & HM \\
\hline G 1 & -1.46556 & -0.81085 & -0.78883 & -2.35806 & 20.48 & 23.84 & 23.84 & 33.20 & 44.30 & 7.95 & 43.68 & 0.9452 & 0.9388 & 43.10 \\
\hline G 2 & -1.7694 & -3.4087 & -3.0468 & -2.1993 & 29.85 & 50.92 & 51.77 & 61.93 & 49.01 & 10.26 & 48.02 & 1.0405 & 1.0313 & 47.07 \\
\hline G 3 & -0.9465 & -0.8923 & -2.0709 & -3.0099 & 8.54 & 8.56 & 17.55 & 25.90 & 46.37 & 6.39 & 45.96 & 0.9935 & 0.9890 & 45.54 \\
\hline G 4 & 0.6787 & 1.0642 & 2.4010 & 0.4187 & 4.39 & 5.56 & 17.11 & 30.39 & 49.70 & 7.60 & 49.19 & 1.0634 & 1.0585 & 48.69 \\
\hline G 5 & -0.9094 & -2.9592 & -3.8923 & -3.8936 & 7.89 & 40.83 & 46.46 & 48.33 & 45.93 & 9.18 & 45.12 & 0.9771 & 0.9693 & 44.34 \\
\hline G 6 & 0.1274 & 0.7680 & -0.1851 & 0.8515 & 0.15 & 3.37 & 9.25 & 12.39 & 48.19 & 7.05 & 47.73 & 1.0305 & 1.0282 & 47.27 \\
\hline G 7 & -0.0748 & 0.5780 & -0.4986 & -0.5864 & 0.05 & 3.39 & 10.89 & 29.31 & 48.09 & 8.86 & 47.35 & 1.0236 & 1.0189 & 46.64 \\
\hline G 9 & -0.8798 & 1.1357 & -0.0166 & -1.0811 & 7.38 & 39.23 & 47.82 & 51.21 & 45.09 & 7.31 & 44.55 & 0.9653 & 0.9561 & 44.03 \\
\hline G 10 & 2.1685 & 1.0045 & 1.6471 & 5.0999 & 44.83 & 55.45 & 58.12 & 93.29 & 48.95 & 9.29 & 48.12 & 1.0442 & 1.0319 & 47.28 \\
\hline G 11 & 2.7459 & 1.1884 & 0.3578 & -0.4409 & 71.89 & 90.91 & 95.37 & 101.45 & 49.65 & 10.75 & 48.61 & 1.0555 & 1.0418 & 47.63 \\
\hline G 12 & 0.4210 & 2.2539 & 4.4233 & 4.2427 & 1.69 & 28.03 & 58.46 & 65.62 & 49.45 & 8.85 & 48.77 & 1.0560 & 1.0479 & 48.14 \\
\hline G 13 & 0.6353 & 1.6718 & 3.1689 & 3.3110 & 3.85 & 12.27 & 26.77 & 49.26 & 49.66 & 7.07 & 49.19 & 1.0645 & 1.0573 & 48.71 \\
\hline G 14 & -2.7918 & -3.3722 & -3.6594 & -3.4256 & 74.31 & 76.95 & 77.48 & 92.53 & 40.50 & 8.99 & 39.59 & 0.8625 & 0.8452 & 38.68 \\
\hline G 15 & 2.6753 & 4.8247 & 3.1466 & 4.3196 & 68.23 & 104.46 & 122.67 & 129.75 & 45.83 & 9.33 & 44.92 & 0.9805 & 0.9568 & 43.98 \\
\hline G 16 & 0.9401 & 0.1787 & 1.5750 & 0.6470 & 8.43 & 12.97 & 25.58 & 33.40 & 44.72 & 8.25 & 44.03 & 0.9528 & 0.9463 & 43.34 \\
\hline
\end{tabular}

ASV and ASV1 observed suitability of (G7, G6, G4) along with unsuitable performance forG15, G11 (Table 6). Considering first two IPCAs in ASV \& ASV1 measures utilized $66.3 \%$ of GxE interaction sum of squares. The two
IPCAs have different values and meanings and the ASV and ASV1 parameters using the Pythagoras theorem and to get estimated values between IPCA1 and IPCA2 scores to produce a balanced measure between the two IPCA scores [11, 12]. 
Also, ASV and ASV1 measures used advantages of cross validation due to computation from first two significant IPCAs. Total of $75.9 \%$ of GxE interaction utilized by Type-3 measures, values of EV3preferred G6, G1, G7 and unstable performance of G15, G12 whereas D3 pointed towards G6, G7, G4 and G15, G11 whereas SIPC3 pointed towardsG5, G14, G2 \& G12, G13; ASTAB3 measure considered G6, G7, G4 \& G15, G11 (Tables 5 \& 6). Genotypes G6, G1, G4 pointed outby least values EV5 and maximum values found forG10, G15, SIPC5 measure identifiedG2, G8, G10and G9, G4 whereas D5 considered G6, G4, G7 as suitable\& G15, G11 as unsuitable ones; ASTAB5 selectedG6, G3, G7 as suitable \&G15, G11 as unsuitable genotypes. Composite measures MASV selected G6, G3, G7 genotypes and G15, G11 however
MASV1selected G6, G7, G3 for stable performance and G15, G11 would not be recommended for cultivation due to unstable yield behavior. Highly significant differences had been observed among genotypes yield;average yield was considered as an important measure to assess the potential yield of genotypes. G4, G13 and G11 wheat genotypes achieved higher yield as compared to G14, G1. Adaptability index (GAI) pointed towards G13, G4, G12 as of stable adaptations whereas G14 \& G1 would be of unstable nature. HM and PRVG measures identified G13, G4, G12 and G14 \& G1 for general and specific adaptations. MHPRVG found G4, G13, G12 as genotypes for broad adaptations for studied environmental conditions and G14, G1 for specific conditions.

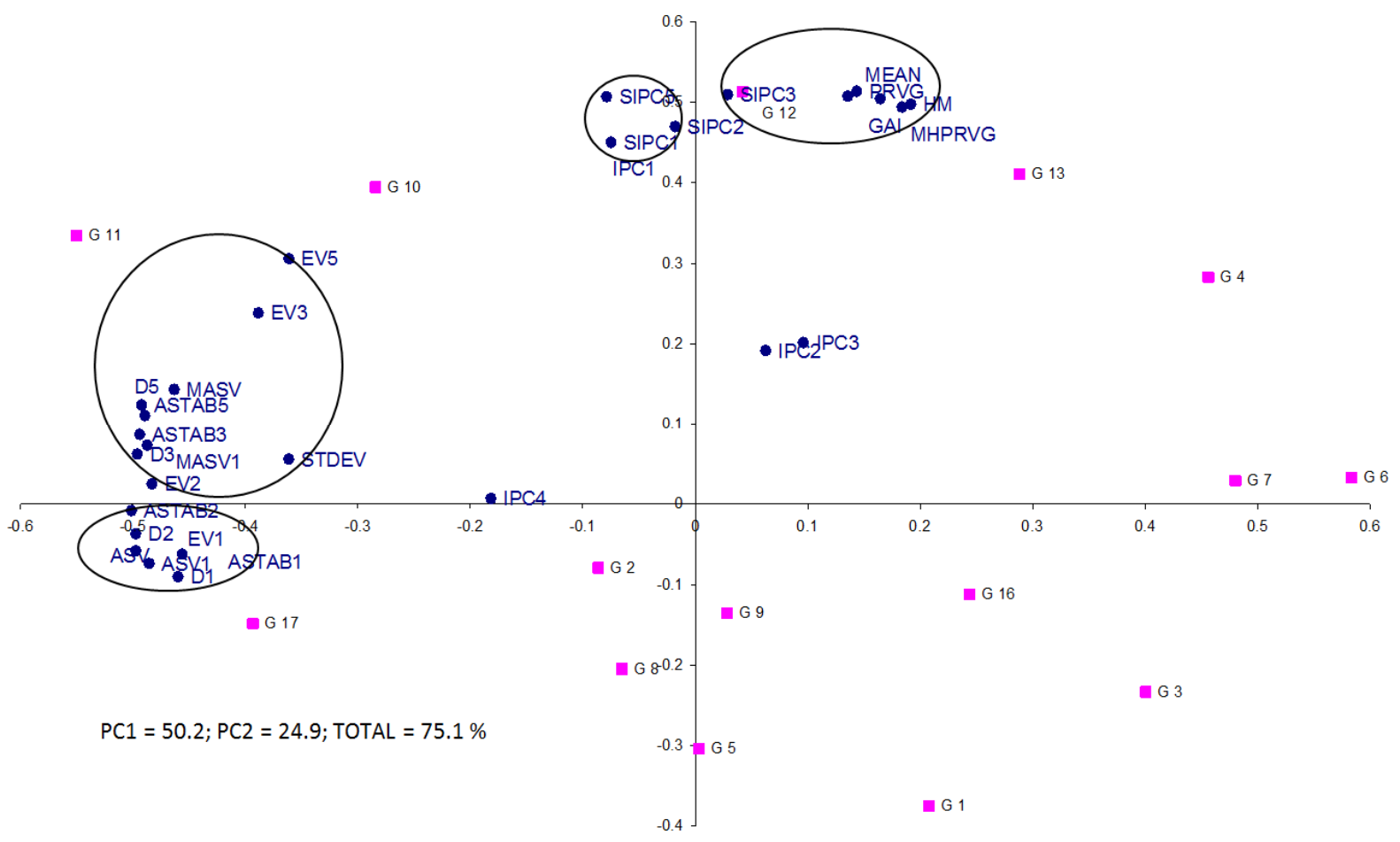

Figure 1. Biplot analysis of AMMI and yield based estimates (2017-18).

Biplot analysis based on first two significant principal components helped to visualize the relationships among AMMI and yield based other measures [19]. In total, PC1 and $\mathrm{PC} 2$ accounted for more than $75.1 \%$ total variation among measures (Figure 1). Largest cluster consisted of D3, D5, EV2, EV3, EV5, ASTAB3, ASTAB5, MASV1, MASV and Stdev measures. Second nearby cluster consisted of D1, D2, EV1, ASV, ASV1 ASTAB1, ASTAB2, measures. Third close cluster of smaller size clubbed IPC1, SIPC1, SIPC5 measures. Fourth cluster kept all mean based measures, Mean, HM, PRVG, MHPRVG, GAI and SIPC3. Measures IPC2, IPC3 \& IPC4 were observed as outliers' measures.

\subsection{Second Year of Study (2018-19)}

Estimated sums of squares for GxE signal and GxE noise were $66.6 \%$ and $33.4 \%$ respectively. Note that the SS for GxE signal is 1.26 times that for genotypes main effects.
Hence, narrow adaptations are important for this dataset. Even just IPC1 alone is 0.97 times the genotypes main effects. Also note that GxE noise is 0.63 times the genotypes main effects. Highly significant environments (44.1), GxE interaction (20.4) and genotypes (10.8) were observed by ANOVA analysis. Extent of GxE interaction variation accounted by each of highly significant IPCA's for AMMI based measures, as type-1 benefited $51.2 \%$, type- 2 measures utilized $66.3 \%$, type 3 measures used up to $79.3 \%$, contributions of other non significant IPCA4, IPCA5, IPCA6 and IPCA7 were of 8.5, 5.8, 3.6 and $1.7 \%$ respectively (Table 4). Ranking of genotypes as per values of EV1 observed (G9, G11, G6) for least and large values by (G1, G2) while D1corresponds to $(\mathrm{G} 9, \mathrm{G} 11, \mathrm{G} 6)$ and $(\mathrm{G} 1, \mathrm{G} 2)$, SIPC1 for $(\mathrm{G} 1, \mathrm{G} 10, \mathrm{G} 7)$ and $(\mathrm{G} 2, \mathrm{G} 3)$ and for ASTAB1 were (G9, $\mathrm{G} 11, \mathrm{G} 6)$ \& (G1, G2). EV2 measure pointed towards (G9, G6, G11) as desirable along with undesirable genotypes as 
(G1, G5); values of D2 selected (G9, G11, G6) \& (G1, G5), while for SIPC2 were $(\mathrm{G} 1, \mathrm{G} 7, \mathrm{G} 5)$ \& $(\mathrm{G} 2, \mathrm{G} 1)$ and ASTAB2 values favoured(G6, G6, G11) \& (G1, G5) (Tables 7 and 8). ASV observed (G9, G6, G11) and ASV1 recommended (G9, G11, G6) as with stable performance and unsuitable performance forG1, G2 (Table 5). First two IPCAs in ASV \& ASV1 measures utilized $66.3 \%$ of GxE interaction sum of squares. Type-3 measures had exploited $79.3 \%$ of GxE interaction and values of EV3preferred G9, G8, G4 and unstable performance of G1, G3 whereas D3 pointed towards G9, G4, G11 and G1, G3 whereas SIPC3 pointed towardsG1, G7, G5 \& G3, G11; ASTAB3 measure considered G9, G4, G11 \& G1, G3 (Tables 7 \& 8). Composite measures MASV \& MASV1selected G9, G6, G11 genotypes for stable performance and G1, G2 would not be recommended for cultivation due to unstable yield behavior. Average yield was considered as an important measure to assess the genotypes potential as highly significant yield differences were exhibited. G4, G8, G6 genotypes maintained higher yields as compared to G1 \& G11. GAI pointed towards G4, G7, G8 as of stable adaptation and G1 \& G11 would be unstable. HM, PRVG and MHPRVG measures identified G4, G7, G8 and G1 \& G11 for general and specific adaptations respectively. Lower values of standard error anticipated consistent yield performance forG4, G10, G1 genotypes as far as considered locations were considered. Three clusters were observed among studied measures by biplotanalysis by considering first two significant principal components $(80.3 \%$ total variation) (Figure 2). Larger cluster consisted of EV1, EV2, EV3, D1, D2, D3, ASV, ASV1, MASV, MASV1, ASTAB1, ASTAB2\& ASTAB3. Second cluster comprised of SIPC1, SIPC2, SIPC3, IPC1 \& standard deviation. Third cluster clubbed mean based measures, Mean, HM, PRVG, MHPRVG and GAI.

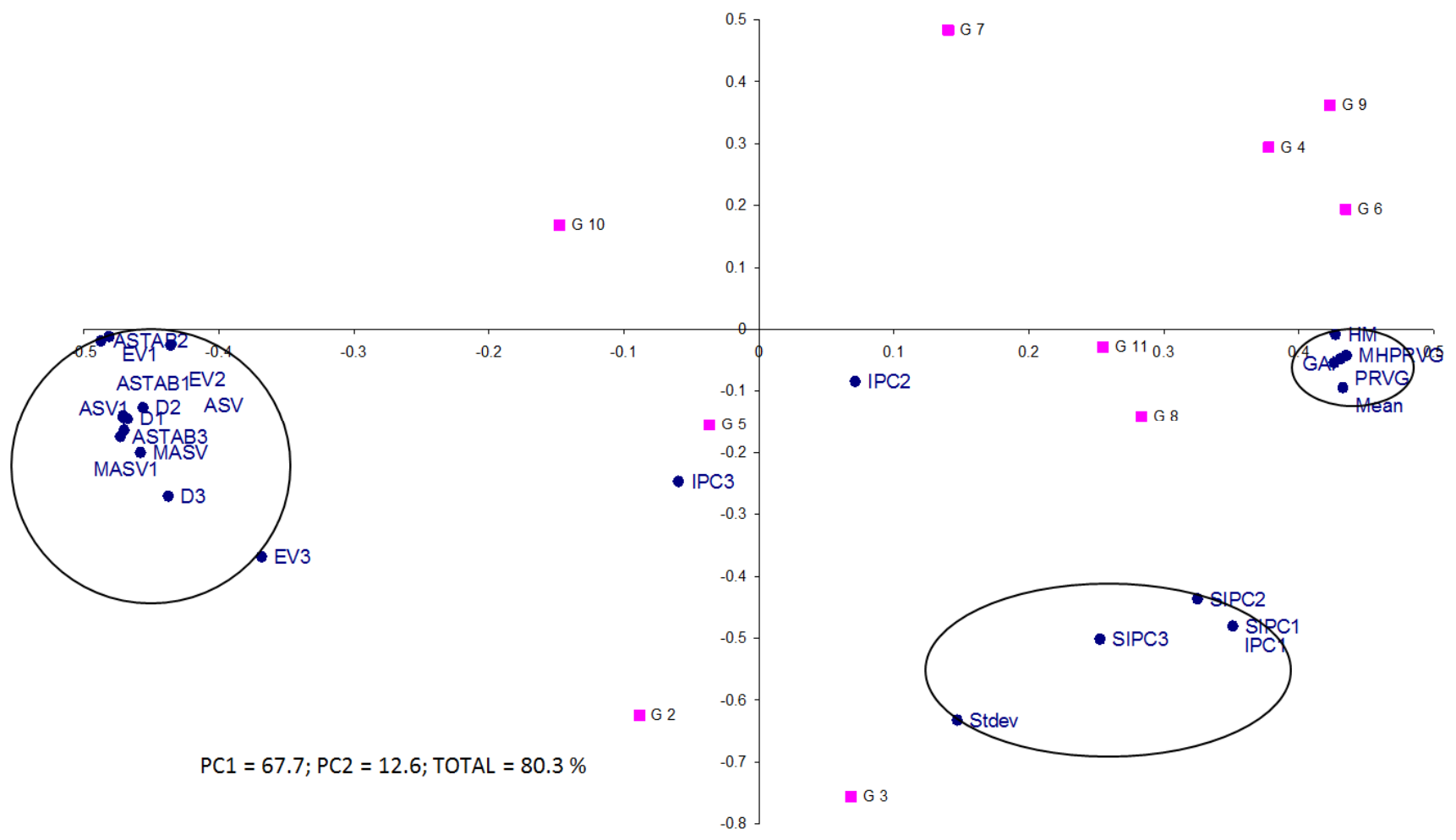

Figure 2. Biplot analysis of AMMI and yield based estimates (2018-19).

Table 8. Principal components analysis of genotypes (2018-19).

\begin{tabular}{|c|c|c|c|c|c|c|c|c|c|c|c|c|c|}
\hline & ASV & ASV1 & MASV & MASV1 & IPC1 & IPC2 & IPC3 & EV1 & EV2 & EV3 & D1 & D2 & D3 \\
\hline G 1 & 7.76 & 14.21 & 7.84 & 14.26 & -4.1990 & -0.7740 & 0.7300 & 0.2681 & 0.1424 & 0.1003 & 11.96 & 12.11 & 12.23 \\
\hline G 2 & 4.09 & 7.20 & 4.58 & 7.52 & 2.0915 & 1.3958 & -1.4129 & 0.0665 & 0.0605 & 0.0604 & 5.96 & 6.87 & 7.66 \\
\hline G 3 & 3.00 & 5.51 & 4.10 & 6.18 & 1.6304 & -0.0367 & 2.8037 & 0.0404 & 0.0202 & 0.0928 & 4.64 & 4.64 & 8.17 \\
\hline G 4 & 1.78 & 2.68 & 2.24 & 3.06 & -0.7096 & 1.2083 & 0.3737 & 0.0077 & 0.0242 & 0.0176 & 2.02 & 3.58 & 3.69 \\
\hline G 5 & 3.23 & 4.51 & 4.28 & 5.43 & 1.1078 & -2.5122 & -0.6699 & 0.0187 & 0.0975 & 0.0695 & 3.15 & 6.91 & 7.09 \\
\hline G 6 & 1.13 & 2.07 & 1.92 & 2.59 & 0.6118 & -0.1126 & -1.5524 & 0.0057 & 0.0030 & 0.0263 & 1.74 & 1.76 & 4.12 \\
\hline G 8 & 2.69 & 4.82 & 2.81 & 4.89 & 1.4089 & -0.7339 & 0.1331 & 0.0302 & 0.0226 & 0.0153 & 4.01 & 4.40 & 4.41 \\
\hline G 9 & 0.59 & 0.97 & 0.88 & 1.18 & 0.2730 & -0.3034 & 0.5614 & 0.0011 & 0.0019 & 0.0044 & 0.78 & 1.07 & 1.72 \\
\hline G 10 & 3.58 & 5.79 & 4.29 & 6.32 & -1.6050 & 2.0218 & -0.8878 & 0.0392 & 0.0767 & 0.0591 & 4.57 & 6.73 & 7.06 \\
\hline G 11 & 1.44 & 2.02 & 2.11 & 2.59 & 0.5003 & 1.1128 & 0.9644 & 0.0038 & 0.0192 & 0.0222 & 1.42 & 3.07 & 3.84 \\
\hline
\end{tabular}


Table 9. AMMI based estimates of genotypes (2018-19).

\begin{tabular}{|c|c|c|c|c|c|c|c|c|c|c|c|c|}
\hline & SIPC1 & SIPC2 & SIPC3 & ASTAB1 & ASTAB2 & ASTAB3 & MEAN & STDEV & GAI & RPGV & MHRPGV & HМ \\
\hline G 1 & -4.20 & -4.97 & -4.24 & 142.99 & 146.58 & 149.64 & 38.32 & 5.31 & 37.98 & 0.8243 & 0.8022 & 37.65 \\
\hline G 2 & 2.09 & 3.49 & 2.07 & 35.48 & 47.13 & 58.61 & 47.16 & 9.79 & 46.33 & 0.9965 & 0.9879 & 45.60 \\
\hline G 3 & 1.63 & 1.59 & 4.40 & 21.56 & 21.57 & 66.76 & 48.40 & 10.22 & 47.55 & 1.0226 & 1.0137 & 46.80 \\
\hline G 4 & -0.71 & 0.50 & 0.87 & 4.08 & 12.82 & 13.62 & 49.55 & 5.28 & 49.31 & 1.0584 & 1.0534 & 49.09 \\
\hline G 5 & 1.11 & -1.40 & -2.07 & 9.95 & 47.71 & 50.29 & 48.28 & 9.46 & 47.56 & 1.0220 & 1.0149 & 46.96 \\
\hline G 6 & 0.61 & 0.50 & -1.05 & 3.04 & 3.11 & 16.97 & 48.99 & 7.86 & 48.45 & 1.0392 & 1.0356 & 47.94 \\
\hline G 8 & 1.41 & 0.68 & 0.81 & 16.10 & 19.32 & 19.42 & 49.15 & 8.78 & 48.53 & 1.0414 & 1.0369 & 47.99 \\
\hline G 9 & 0.27 & -0.03 & 0.53 & 0.60 & 1.15 & 2.97 & 46.29 & 6.82 & 45.88 & 0.9835 & 0.9815 & 45.51 \\
\hline G 10 & -1.61 & 0.42 & -0.47 & 20.89 & 45.34 & 49.88 & 47.29 & 5.29 & 47.03 & 1.0113 & 1.0025 & 46.76 \\
\hline G 11 & 0.50 & 1.61 & 2.58 & 2.03 & 9.44 & 14.78 & 45.33 & 8.43 & 44.65 & 0.9592 & 0.9529 & 44.01 \\
\hline
\end{tabular}

\section{Conclusions}

AMMI analysis has been proved as an effective tool to explore complex GxE interaction under multi environmental trials. Large number of AMMI based measures had been studied as each measures related to a different concept of stability. Recent analytic measures for adaptability of wheat genotypes exhibited affiliation withAMMI based measures exploiting number of significant IPC scores.

\section{Conflict of Interest}

All the authors do not have any possible conflicts of interest.

\section{Acknowledgements}

The wheat genotypes were evaluated at coordinated centers of AICW\&BIP across the country. Authors sincerely acknowledge the hard work of all the staff for field evaluation and data recording.

\section{References}

[1] Agahi K., JafarAhmadi, Hassan AmiriOghan, Mohammad HosseinFotokian and SedighehFabriki Orang (2020)Analysis of genotype $\times$ environment interaction for seed yield in spring oilseed rape using the AMMI model. Crop Breeding and Applied Biotechnology 20 (1): e26502012

[2] Ajay B C, Aravind J, Fiyaz R Abdul, Kumar Narendra, LalChuni, Gangadhar K, Kona Praveen, Dagla M C and Bera S K (2019) Rectification of modified AMMI stability value (MASV). Indian J Genet. 79 (4): 726-731.

[3] Akbarpour O, Dehghani H, Sorkhi B, Guach G (2014) Evaluation of Genotype $\times$ Environment Interaction in Barley (HordeumVulgare L.) Based on AMMI model Using Developed SAS Program. J AgricSci Tech. 16: 919-930.

[4] Annicchiarico P (1997) Joint regression vs AMMI analysis of genotype $\times$ environment interactions for cereals in Italy. Euphytica 94: 53-62.

[5] Bocianowsk J, Warzecha T, Nowosad K, \&Bathelt R (2019) Genotype by environment interaction using AMMI model and estimation of additive and epistasis gene effects for 1000kernel weight in spring barley (Hordeumvulgare L.). Journal of Applied Genetics, 60: 127-135.

[6] Gauch HG (2013) A Simple Protocol for AMMI Analysis of Yield Trials. Crop Science 53: 1860-1869.

[7] Guilly, S., Thomas, D., Audrey, T., Laurent, B., \& Jean-Yves, H. (2017). Analysis of multi environment trials (MET) in the sugarcane breeding program of Re'union Island. Euphytica, 213, 213.

[8] Hongyu K, García-Peña M, de Araújo LB and dos Santos Dias CT (2014) Statistical analysis of yield trials by AMMI analysis of genotype $\times$ environment interaction. Biometrical letters 51: 89-102.

[9] Kendal E, Tekdal S(2016) Application of AMMI Model for Evolution Spring Barley Genotypes in Multi-Environment Trials. Bangladesh J. Bot. 45 (3): 613-620.

[10] Mohammadi R and Amri A(2008) Comparison of parametric and non-parametric methods for selecting stable and adapted durum wheat genotypes in variable environments. Euphytica 159: 419-432.

[11] Purchase JL (1997) Parametric analysis to describe $\mathrm{G} \times \mathrm{E}$ interaction and yield stability in winter wheat. Ph.D. thesis. Dep. of Agronomy, Faculty of Agriculture, Univ. of the Orange Free State, Bloemfontein, South Africa.

[12] Purchase, J. L., Hatting, H., \& Van Deventer, C. S. (2000). Genotype $\mathrm{x}$ environment interaction of winter wheat (T.aestivum) in South Africa: Stability analysis of yield performance. South African Journal of Plant and Soil, 17 (3), 101-107.

[13] Rao AR, Prabhakaran VT (2005) Use of AMMI in simultaneous selection of genotypes for yield and stability. Journal of the Indian Society of Agricultural Statistics 59: 7682.

[14] Resende MDV de andDuarte JB. 2007. Precision and quality control in variety trials. PesquisaAgropecuaria Tropical. 37 (3): 182-194.

[15] Shahriari Z, Heidari B, Dadkhodaie A (2018) Dissection of genotype $\times$ environment interactions for mucilage and seed yield in Plantago species: Application of AMMI and GGE biplot analyses. PLoS ONE 13 (5): e0196095

[16] Sneller CH, Kilgore-Norquest L, Dombek D (1997) Repeatability of yield stability statistics in soybean. Crop Science, 37: 383-390. 
[17] Tadesse T, Sefera G and Tekalign A (2018) Genotypes Environment interaction analysis for Ethiopian mustard (Brassica carinata L.) genotypes using AMMI model. Journal of Plant Breeding and Crop Science 10: 86-92.

[18] Tekdal S, Kendal E (2018) AMMI Model to Assess Durum Wheat Genotypes in Multi-Environment Trials. J AgrSci Tech. 20: 153-166.

[19] Yang, R.-C., J. Crossa, P. L. Cornelius, and J. Burgueño. 2009. Biplot analysis of genotype $\mathrm{x}$ environment interaction: Proceed with caution. Crop Sci. 49: 1564-1576.
[20] Zali H, Farshadfar E, Sabaghpour SH, Karimizadeh R (2012) Evaluation of genotype $\times$ environment interaction in chickpea using measures of stability from AMMI model. Annals of Biological Research 3 (7): 3126-3136.

[21] Zobel R(1994) Stress resistance and root systems. In Proceedings of the Workshop on Adaptation of Plants to Serious Stresses. 1-4 August. INTSORMIL Publication 94-2, Institute of Agriculture and Natural Recourses. Lincoln, USA: University of Nebraska. 